ISSN 2447-9071

doi https://doi.org/10.36414/rbmc.v6i15.50
Contato para correspondência: Lucas Luiz de Lima Silva

E-mail:

limabiomed@hotmail.com

Conflito de interesse: Não

Financiamento: Recursos próprios

Recebido: $22 / 07 / 2020$

Aprovado: 05/08/2020

\section{Contagem de linfócitos TCD4 + e carga viral em pacientes HIV+ de um laboratório de referência}

\section{Counting of TCD4+ lymphocyte and viral load in HIV+ patients in reference laboratory}

Hildegard da Costa Souza', Xisto Sena Passos'1, Milton Camplesi Júnior1, Antonio Márcio Teodoro Cordeiro Silva ${ }^{2,3}$, Ana Karoline Silva Oliveira ${ }^{4}$, Larissa de Oliveira Rosa Marques ${ }^{4}$, Juliana Menara de Souza Marques ${ }^{1,4}$, Valéria Bernadete Leite Quixabeira ${ }^{2,3}$, Lucas Luiz de Lima Silva ${ }^{1,4}$

1 Universidade Paulista - UNIP

${ }^{2}$ Pontifícia Universidade Católica de Goiás - PUC Goiás

${ }^{3}$ Faculdade da Polícia Militar - FPM

${ }^{4}$ Universidade Federal de Goiás - UFG

\section{Resumo}

Esteestudo teve por objetivo avaliar o número de linfócitos $T C D 4+$ e carga viral em pacientes infectados com HIV, atendidos em laboratório de referência em Goiânia, Goiás. Trata-se de pesquisa observacional, longitudinale retrospectiva. Foram avaliados prontuários eletrônicos de pacientessubmetidos ao exame de contagem de linfócitos TCD4 + e carga viral, no periodo de janeiro de 2015 a dezembro de 2017. Dos 14 pacientes avaliados, 35,7\% ( $n=5 / 14)$ obtiveram, no primeiro exame, resultados abaixo de 200 células $/ \mathrm{mm}^{3}$ e a quantificação da carga viral foi expressiva. Na quantificação de linfócitos TCD4+, 85,7\% ( $n=12 / 14)$ dos pacientes possuíam valores abaixo do valor de referência (VR) mínimo, quando fizeramo primeiro exame, após o diagnóstico, e todos estes tiveram a carga de RNA viral acima do valor mínimo quantificável (VR: 560 células $/ \mathrm{mm}^{3}$ a 2700 células $/ \mathrm{mm}^{3}$ ). Foi constatado que, dos 12 dos pacientes que no início apresentaram valores abaixo do normal, 4 deles (33,3\%) conseguiram atingir valores normais de linfócitos $T C D 4+$, após o tratamento, e 50,0\% ( $n=6 / 12)$ dos pacientes alcançaram níveis indetectáveis de carga viral. O monitoramento imune, feito pela citometria de fluxo, aliado a quantificação da carga viral de RNA, ganha notoriedade, pois, pormeio destas ferramentas, pode-se determinaro grau de comprometimento imunológico dos pacientes e a eficácia do tratamento com antirretroviral.

Palavras-Chave: Imunologia, HIV, Carga viral, Linfócitos T CD4.

\begin{abstract}
This study aimed to analyze the number of TCD4 + lymphocytes and viral load in HIV-infected patients treated at the reference laboratory in Goiania-Goiás. This is an observational, longitudinal and retrospective study. They underwent clinical tests on patients who underwent TCD4 + lymphocyte count and viral load, from January 2015 to December 2017. Of the 14 patients evaluated, 35.7\% ( $n=5 / 14)$ obtained, in the firstexam, results below 200 cells $/ \mathrm{mm}^{3}$ and the quantification of the vitreous load was significant. In the quantification of CD4 + Tlymphocytes, $85.7 \%(n=12 / 14)$ of the patients had values below the minimum reference value (VR), when they underwent the first exam, after diagnosis, and all of them had an RNA load. virus above the minimum quantifiable value (VR: 560 cells $/ \mathrm{mm}^{3}$ to 2700 cells $/ \mathrm{mm}^{3}$ ). It was found that, of the 12 patients who initially presented values belownormal, 4 of them (33.3\%) managed to reach normal values of CD4 + Tlymphocytes, after treatment, and $50.0 \%(n=6 / 12)$ of patients reached undetectable levels of viral load. Immunemonitoring, performed by flow cytometry, combined with the quantification of RNA viral load, gains notoriety because, through these tools, it is possible to determine the degree of patients'immune compromise and treatment with antiretroviral.
\end{abstract}

Keywords: Immunology, HI, Viral load, CD4 T-Lymphocytes. 


\section{Introdução}

A síndrome da imunodeficiência adquirida (SIDA/AIDS) recebeu notoriedade, após o seu relato, em 1981, com a observação de manifestações clínicas de infecções características de pacientes com imunossupressão ou imunodepressão. Posteriormente, com o isolamento e a caracterização do Vírus da Imunodeficiência Humana (HIV), descobriu-se que a síndrome era resultante do estágio avançado da infecção pelo HIV, que utiliza células T CD4 + para se multiplicar, afetando, assim, a resposta imune a patógenos'.

De acordo com o boletim epidemiológico do Ministério da Saúde (MS) do Brasil, no ano de 2016, houve 37.884 casos de infecções por HIV notificados. Considerando todo o território nacional, a maioria dos casos era proveniente da região Sudeste, com 15.759 (41,6\%), seguida das regiões: Nordeste, com 7.693 (20,3\%), Sul, com 7.688 (20,3\%), Norte, com 3.912 $(10,3 \%)$ e, por fim, Centro-Oeste, com 2.832 (7,5\%) de casos. Já em relação à SIDA, de 1980 a junho 2017, foram identificados 882.810 casos, no Brasil. Nos últimos cinco anos, em média, 40 mil novos casos estão sendo notificados a cada ano ${ }^{2}$.

As células do sistema imune, em conjunto com os demais mecanismos de defesa, como: barreira epitelial, antibióticos presentes no epitélio e proteínas plasmáticas, apresentam papel fundamental no combate a patógenos. A relevância do sistema imune adquirido, composto pelos linfócitos $T$ e $B$, merece destaque, pois objetiva eliminar microrganismos intra e extracelulares, com elevada especificidade e efetividade ${ }^{3}$.

Os linfócitos T se subdividem em T CD4+ e T CD8+. O linfócito $T C D 4+$, ou auxiliar, contribui para a produção de anticorpos pelos linfócitos $B$ e na ativação das células fagocitárias que destroem microrganismos. Já o linfócito T CD8+, ou citolítico, provoca a lise de células que estão infectadas por microrganismos intracelulares4. A diminuição dos linfócitos T CD4 +, ao longo do tempo compromete o sistema imunológico, tornando-o menos eficiente no combate a patógenos agressores. Este quadro aumenta a suscetibilidade individual a doenças oportunistas que são inofensivas em pessoas hígidas ${ }^{5}$.

A infecção pelo HIV começa com a etapa de adsorção, que compreende a ligação do vírion à superfície da célula alvo. Esta é mediada por uma interação de alta afinidade entre o domínio extracelular da glicoproteína viral gp120 e receptores celulares específicos, sendo o CD4 o principal receptor. Além disso, um grupo de receptores de quimiocinas, CCR5 e CXCR4, têm sido identificados como os principais correceptores in vivo para o HIV-1. Assim, após a ligação da gp120 ao receptor celular CD4, ocorrem alterações conformacionais que facilitam a ligação ao correceptor e subsequente entrada viral, evento decorrente da fusão do envelope viral com a membrana celular, um processo facilitado pela glicoproteína gp41 $1^{4,5}$.

Para o diagnóstico da infecção do HIV, são utilizados testes sorológicos e moleculares. Dentre eles, tem-se o padrão ouro, que consiste em imunoensaio (IE), comumente, de quarta geração, para triagem e teste confirmatório Western Blot (WB)6. Já a AIDS, que é resultante do estado avançado da infecção, diagnóstica pela quantificação, numérica e percentual, de linfócitos T CD4+, já que a segunda sofre menor alteração de seus valores. A quantificação dos linfócitos T CD4+ é obtida por volume de sangue e os valores abaixo de 500 células/ $\mathrm{mm}^{3}$, ou inferiores a $24 \%$, são considerados alterados. Paciente com contagem de células abaixo de 200 células $/ \mathrm{mm}^{3}$ estão suscetíveis a doenças oportunistas, como pneumocistose e a toxoplasmose ${ }^{7}$.

Diante desse cenário, o monitoramento das subpopulações de linfócitos TCD4+e TCD8+e da carga viral, se faz necessário, pois a diminuição de linfócitos coloca o indivíduo em estado de supressão ou depressão imunológica, deixando-o suscetíveis a diversas patologias. Para isso, a quantificação, por meio da citometria de fluxo, tornou-se importante ferramenta no acompanhamento na contagem de linfócitos TCD4+ eTCD8+, mostrando-se eficaz na determinação do nível de progressão da doença e expondo os riscos de infecções a que o indivíduo está sujeito ${ }^{8}$.

O presente estudo objetivou levantar dados em relação à quantificação do número de linfócitos T CD4+ e da carga viral, em pacientes infectados com HIV, no período de 2015 ao ano de 2017, atendidos em laboratório de referência de Goiânia-Goiás.

\section{Métodos}

Trata-se de estudo observacional, longitudinal e retrospectivo, com avaliação de prontuários eletrônicos, de pacientes que se submeteram aos exames de contagem de linfócitos T CD4 + e carga viral. A contagem de células T CD4+, para acompanhamento da progressão da doença e monitoramento do tratamento em indivíduos infectados pelo HIV-1, representa uma das principais aplicações clínicas da citometria de fluxo, metodologia utilizada para o estudo morfológico, fenotípico e funcional de células através da detecção da dispersão da luz e da fluorescência emitida por moléculas (fluorocromos) ligadas às mesmas.

A citometria de fluxo é um método mais sensível e simples de imunofenotipagem quando comparado a técnicas clássicas, como imunocitoquímica e imunofluorescência, ambas analisadas por microscopia. A imunofenotipagem por citometria de fluxo é considerada o padrão ouro para a quantificação 
de células T CD4 +. Essa técnica permite a identificação e/ou a quantificação simultânea e rápida de múltiplos antígenos em um elevado número de células pela análise da presença/ ausência de antígenos expressos na superfície ou no interior da célula ${ }^{8}$.

Em relação a detecção quantitativa de ácido nucleico viral, destaca-se a utilização da reação em cadeia da polimerase em tempo real (PCR-RT), técnica quantitativa destinada a monitorar a infecção pelo HIV, orientar o tratamento e prever a evolução futura da doença. Com base nessas quantificações, sabe-se que níveis altos de RNA plasmáticos estão associados à queda rápida na população de linfócitos $C D 4$ e à progressão mais rápida para AIDS.

O grupo amostral do presente estudo foi constituído por pacientes maiores de 18 anos, de ambos os sexos, que fizeram a contagem de linfócitos T CD4+ e carga viral, no período de janeiro de 2015 a dezembro de 2017. Todos os participantes desta pesquisa possuíam diagnóstico prévio da infecção por HIV.

A amostragem inicial era constituída de 162 pacientes. Foram excluídos 57 pacientes que obtiveram o diagnóstico sorológico positivo para HIV, mas não fizeram a monitorização, 22 pacientes receberam o diagnóstico sorológico negativo para HIV, 8 pacientes não possuíam a idade mínima de 18 anos, 18 pacientes não realizaram o segundo exame, 43 pacientes não possuía um dos parâmetros analisados. Foram incluídos, nesse estudo, 14 pacientes que tinham o diagnóstico de HIV e fizeram a monitorização imune para a doença.

Os dados coletados, a partir dos prontuários, foram: idade, sexo e ano do diagnóstico sorológico. Os dados foram inseridos em planilha eletrônica com o auxílio do software Excel e, posteriormente, foram analisados por meio de estatística descritiva.

Esta pesquisa foi aprovada pelo Comitê de Ética em Pesquisa da Universidade Paulista (UNIP), sob o parecer de número 3.190.675.

\section{Resultados}

Na população deste estudo, todos os pacientes (14) eram do sexo masculino, com média das idades de 29,7 anos. Por meio da quantificação de linfócito T CD4+, percebeu-se que $85,7 \%(n=12 / 14)$ dos pacientes estavam abaixo do valor de referência (VR) mínimo, quando comparado aos valores relativos ao primeiro exame, após o diagnóstico de HIV, e todos os 14 pacientes tiveram a contagem de RNA viral acima do normal (VR: 560 células $/ \mathrm{mm}^{3}$ a 2700 células $/ \mathrm{mm}^{3}$ ) (Tabela 1).

Tabela 1. Quantificação de LT CD4+ no primeiro exame de monitorização imune e carga viral.

\begin{tabular}{|c|c|c|c|c|c|c|c|c|c|}
\hline Paciente & Gênero & Idade & Diagnóstico & Ano/Mês & Exame & $\begin{array}{l}\text { Linfócitos } \\
\text { totais }\end{array}$ & CD $4 \%$ & $\mathrm{CD} 4 \mathrm{~mm}^{3}$ & $\begin{array}{l}\text { HIV-PCR } \\
\text { CÓPIAS/ml }\end{array}$ \\
\hline 1 & $M$ & 35 & 2015 & $2015 / 06$ & 1 & 2850 & 16,1 & 458,9 & 50 \\
\hline 2 & $M$ & 34 & 2015 & $2015 / 08$ & 1 & 1305 & 16,7 & 217,9 & 1.273 \\
\hline 3 & M & 25 & 2015 & $2015 / 11$ & 1 & 3268 & 28,8 & 941,2 & 2.512 \\
\hline 4 & $M$ & 22 & 2015 & $2015 / 12$ & 1 & 1517 & 13,2 & 200,2 & 593.205 \\
\hline 5 & $M$ & 33 & 2014 & $2014 / 07$ & 1 & 2996,4 & 26,9 & 806 & 8.792 \\
\hline 6 & $M$ & 32 & 2015 & $2015 / 09$ & 1 & 2450 & 20 & 490 & 23.971 \\
\hline 7 & $M$ & 20 & 2015 & $2015 / 05$ & 1 & 2952 & 16,7 & 493 & 67.730 \\
\hline 8 & $M$ & 32 & 2016 & $2016 / 02$ & 1 & 411 & 1,7 & 7 & 560.517 \\
\hline 9 & M & 26 & 2016 & $2016 / 01$ & 1 & 1092 & 4,6 & 50,2 & 140.938 \\
\hline 10 & $M$ & 41 & 2016 & $2016 / 01$ & 1 & 867 & 6,2 & 53,8 & 123.311 \\
\hline 11 & $M$ & 25 & 2016 & $2016 / 05$ & 1 & 1274 & 2,1 & 26,8 & 187.748 \\
\hline 12 & $M$ & 24 & 2016 & $2016 / 08$ & 1 & 1806 & 30,6 & 552,6 & 9.911 \\
\hline 13 & $M$ & 31 & 2015 & $2015 / 3$ & 1 & 1274 & 14,3 & 182,2 & 64.968 \\
\hline \multirow[t]{2}{*}{14} & M & 36 & 2017 & $2017 / 2$ & 1 & 1348,5 & 25,5 & 343,9 & 109.491 \\
\hline & & & & & & V.R & 27 a 57 & 560 a 2700 & INDETECTÁVEL \\
\hline
\end{tabular}


De acordo com o Boletim Epidemiológico de HIV do MS2, a carga viral de HIV é considerada indetectável abaixo de 40 cópias $/ \mathrm{mL}$, baixa entre $40-500$ cópias $/ \mathrm{mL}$ e alta maior ou igual à 100.000 cópias $/ \mathrm{mL}$. Levando em consideração os valores referenciais, dos 14 pacientes, 35,7\% ( $n=5 / 14)$ obtiveram, no primeiro exame, resultados inferiores a 200 células $/ \mathrm{mm}^{3}$ e a contagem de RNA do vírus foi expressiva, representando assim, prognóstico ruim para estes pacientes (Tabela 2).

Tabela 2. Pacientes com contagem de LT CD 4+ abaixo de $200 \mathrm{~mm}^{3}$ e altas taxas de carga viral.

\begin{tabular}{|c|c|c|c|c|c|c|c|c|c|}
\hline Paciente & Gênero & Idade & Diagnóstico & Ano/Mês & Exame & $\begin{array}{l}\text { Linfócitos } \\
\text { totais }\end{array}$ & CD $4 \%$ & $\mathrm{CD} 4 \mathrm{~mm}^{3}$ & $\begin{array}{l}\text { HIV-PCR } \\
\text { CÓPIAS/mI }\end{array}$ \\
\hline 8 & $M$ & 32 & 2016 & 2016/02 & 1 & 411 & 1,7 & 7 & 560.517 \\
\hline 9 & M & 26 & 2016 & 2016/01 & 1 & 1092 & 4,6 & 50,2 & 140.938 \\
\hline 10 & $M$ & 41 & 2016 & 2016/01 & 1 & 867 & 6,2 & 53,8 & 123.311 \\
\hline 11 & $M$ & 25 & 2016 & $2016 / 05$ & 1 & 1274 & 2,1 & 26,8 & 187.748 \\
\hline \multirow[t]{2}{*}{13} & $M$ & 31 & 2015 & $2015 / 3$ & 1 & 1274 & 14,3 & 182,2 & 64.968 \\
\hline & & & & & & V.R & 27 a 57 & 560 a 2700 & INDETECTÁVEL \\
\hline
\end{tabular}

O paciente 11, na Tabela 2, pelos níveis da contagem absoluta de linfócito T CD4+ e pela carga viral, se encontrava em estado avançado de HIV/SIDA. Realizou a monitorização imune com suspeita de meningite criptocócica e, após 15 dias, evoluiu para o óbito.
Após tratamento e acompanhamento, 33,2\% $(n=4 / 12)$ dos pacientes, que possuíam números abaixo dos valores de referência, tiveram a contagem de linfócito T CD4+ normalizada, com diminuição da carga viral (Tabela 3).

Tabela 3. Pacientes após o tratamento.

\begin{tabular}{|c|c|c|c|c|c|c|c|c|c|}
\hline Paciente & Gênero & Idade & Diagnóstico & Ano/Mês & Exame & $\begin{array}{c}\text { Linfócitos } \\
\text { totais }\end{array}$ & CD $4 \%$ & $\mathrm{CD} 4 \mathrm{~mm}^{3}$ & $\begin{array}{l}\text { HIV-PCR } \\
\text { CÓPIAS/mI }\end{array}$ \\
\hline 1 & $M$ & 35 & 2015 & 2016/09 & 3 & 4465 & 22,1 & 986,8 & 40 \\
\hline 4 & M & 22 & 2015 & $2016 / 05$ & 2 & 3500 & 21,7 & 759,5 & 177 \\
\hline 6 & M & 32 & 2015 & $2016 / 10$ & 3 & 2376 & 28,1 & 667,7 & INDETECTÁVEL \\
\hline \multirow[t]{2}{*}{14} & M & 36 & 2017 & $2017 / 6$ & 2 & 2015 & 33,1 & 667 & INDETECTÁVEL \\
\hline & & & & & & V.R & 27 a 57 & 560 a 2700 & INDETECTÁVEL \\
\hline
\end{tabular}

\section{Discussão}

Estudos têm demostrado que os melhores marcadores para a avaliação do prognóstico da AIDS são a contagem de carga viral e de linfócitos T CD4+. Sendo que, altas taxas de RNA do vírus circulante estão estritamente ligadas ao declínio dos linfócitos T CD4+9,10.

Os pacientes ficam suscetíveis às patologias quando a contagem de linfócito T CD4+ está entre 200 a 500 células $/ \mathrm{mm}^{3}$, como: pneumonias pneumocócicas, tuberculose pulmonar, herpes zoster, candidíase orofaríngea e sarcoma de Kaposi. Abaixo de 200 células $/ \mathrm{mm}^{3}$, o paciente pode desenvolver histoplasmose disseminada e coccidioidomicose. Com contagens críticas, abaixo de 100 células $/ \mathrm{mm}^{3}$, podem ocorrer doenças oportunistas, como toxoplasmose e criptococose ${ }^{11}$, circunstâncias estas, que, comumente, leva o paciente a óbito, devido ao comprometimento da resposta imune contra microrganismos ${ }^{12}$. 
O paciente 11 , que apresentava contagem absoluta de linfócito T CD4+ de 26,8 células $/ \mathrm{mm}^{3}$ e carga viral de 187.748 cópias $/ \mathrm{ml}$, realizou o exame com a indicação de meningite criptocócica e, após 15 dias, não resistiu às complicações e teve morte cerebral. A criptococose é uma patologia oportunista sem importância clínica, até oferecer se tornar importante risco ao grupo de pessoas imunossuprimidas, principalmente com HIV/AIDS. Neste contexto, o fungo é responsável por induzir pacientes a um quadro de meningite, com taxas de mortalidade de 10 a $73 \%$ dos $\operatorname{casos}^{13}$.

Observamos que alguns pacientes $(8,9,10,11$ e 13) apresentaram altas contagens de RNA viral e queda significativa nas contagens de linfócito TCD4+, abaixo de 200 células $/ \mathrm{mm}^{3}$, configurando quadro de HIV avançado. Estes dois parâmetros estão estritamente ligados ao prognóstico da doença, uma vez que altas taxas do vírus refletem na diminuição de linfócito $T$ $\mathrm{CD} 4+$ e oferece risco aos pacientes quanto ao acometimento de patologias oportunistas. Com isso, o diagnóstico precoce tem importante impacto na qualidade de vida desses pacientes, tendo em vista que, por meio da Terapia Antirretroviral (TARV), os reservatórios latentes de linfócitos T CD4+ são eliminados, não gerando depleção do sistema imunológico e induzindo a diminuição da viremia a níveis tão baixos que são incapazes de serem transmitidos ${ }^{5}$.

Segundo Vermund e Wilson14, diversas são as causas que dificultam o diagnóstico prévio, como por exemplo, a falta de expectativas quanto aos benefícios do tratamento, $\mathrm{o}$ preconceito por parte dos indivíduos, a falta de apoio social, a falha na privacidade do aconselhamento e o bloqueio pessoal. Com base nesses obstáculos, os profissionais da área da saúde têm papel relevante no entendimento da importância do diagnóstico precoce.

Constatamos que, dos 14 pacientes deste estudo, 85,7\% $(n=12 / 14)$ apresentaram contagem de linfócito T CD4+ abaixo dos valores normais de 560 células $/ \mathrm{mm}^{3}$ e a quantificação de RNA do vírus, acima do nível indetectável ( $>40.000$ cópias $/ \mathrm{mL}$ ). Com a terapia antirretroviral e o acompanhamento, 33,2\% ( $n=4 / 12)$ dos pacientes, que no início estavam com níveis fora do normal, conseguiram elevar a contagem absoluta de linfócito T CD4+ a níveis acima dos valores de referência e reduzir a carga viral drasticamente. Dos 14 pacientes, 35,7\% ( $n=5 / 14)$ obtiveram, no primeiro exame, resultados abaixo de 200 células $/ \mathrm{mm}^{3}$, caracterizando a AIDS. O tratamento, pormeio de antirretrovirais, tem o objetivo de melhorar a qualidade de vida do paciente, bem como a sua sobrevida, sendo necessário o uso contínuo, que provoca efeitos colaterais severos aos seus adeptos, dificultando a adesão ao tratamento ${ }^{15}$.

As diretrizes atuais sugerem o tratamento TARV logo no início do diagnóstico, pois estudos demostraram que paci- entes que se submeteram ao tratamento, com o quadro de HIV avançado, estavam suscetíveis à progressão da doença de forma acelerada, em comparação àqueles que iniciaram a terapia TARV precocemente ${ }^{16,17}$. Segundo Geocze et al. ${ }^{18}$, a inclusão da terapia antirretroviral de alta potência (HAART) proporcionou diminuição de $33 \%$ no número de óbitos de pacientes com HIV, pois o mesmo atua na inibição da protease do vírus, impedindo a produção de novas cópias ${ }^{19}$.

A predominância de homens jovens diagnosticados com HIV neste estudo corrobora com os dados do boletim epidemiológico do estado de Goiás, que ressalta que, no período de 2013 a 2017, a razão do sexo aumentou, sendo que para cada 1 mulher com HIV, 4,1 casos acontecem em homens. $E$ que a faixa etária de infecção entre 20 a 39 anos é responsável por $70 \%$ dos $\operatorname{casos}^{20}$.

\section{Conclusão}

O diagnóstico precoce, no contexto do HIV/SIDA, está estritamente relacionado à evolução da doença, pois indivíduos que se submetem ao tratamento previamente, comumente, usufruem de melhor qualidade de vida. Assim, o monitoramento imune, feito pela citometria de fluxo, aliado a quantificação da carga viral de RNA, ganha notoriedade, pois, por meio destas ferramentas, pode-se determinar o grau de comprometimento imunológico dos pacientes e a eficácia do tratamento com antirretroviral.

\section{Agradecimentos}

Agradeço à Instituição em que foi realizado este estudo, Instituto Goiano de Hematologia (INGOH), em especial ao Dr. Yuri Vasconcelos pela oportunidade e confiança.

\section{Referências}

1. Secretária Municipal de Saúde. Infecção pelo HIV e AIDS: prevenção, tratamento e diagnóstico na atenção primária. Rio de Janeiro: Núcleo de Publicações e Memória. 2016.

2. Ministério da Saúde. Boletim Epidemiologico - HIV e IST. Brasilia; 2017.

3. Kennedy MA. A brief review of the basics of immunology: the innate and adaptive response. Vet Clin North Am - Small Anim Pract. 2010;40:3:369-79.

4. Abbas AK, Lichtman AH, Pillai S. Imunologia básica: funções e distúrbios do sistema imunológico. Rio de Janeiro: Elsevier; 2013.

5. Loreto S, Pereira JMA. A infecção por HIV - importância das fases iniciais e do diagnóstico precoce. Acta Farm Port. 2012;2(2):5-17. 
6. Ministério da Saúde. Manual técnico para o diagnóstico da infecção pelo HIV. Brasília; 2013.

7. Ministério da Saúde. Contagem de células T CD4 + e testes de carga viral : principais marcadores laboratoriais para indicação e monitorização do tratamento anti-retroviral. unidade de assistência e unidade de laboratório da coordenação nacional de DST/Aids. Brasília; 2013.

8. Silva RC. Avaliação de anticorpos monoclonais CD3, anti-CD4 e anti-CD8 em um teste de imunofenotipagem para a quantificação de linfocitos $T$, utilizando a citometria. Rio de Janeiro: Fundação Oswaldo Cruz; 2005.

9. Mellors JW, Muñoz A, Giorgi JV, Margolick JB, Tassoni CJ, Gupta P, et al. Plasma viral load and CD4+ lymphocytes as prognostic markers of HIV-1. Ann Intern Med.1997;126(12): 946-54.

10. Furini $A A C$, Neves ER, Ferreira GA, Rodrigues JF, Jorge LS, Machado RLD. HIV/AIDS: relação dos níveis de linfócitos T CD4+ e carga viral com o tempo de diagnóstico. Ciências da Saúde. 2016;23(4):7-10.

11. Kempen $\mathrm{JH}$. Medical management of HIV infection. Indian J Ophthalmol. 2008;56(5):385-390.

12. Setianingrum F, Rautemaa-Richardson $R$, Denning DW. Pulmonary cryptococcosis: a review of pathobiology and clinical aspects. Med Mycol. 2019;57(2):133-50.

13. Letícia R, Almeida $G$, Rodrigues E. Cryptococcus spp. em pacientes com HIV/SIDA: revisão da literatura. Ensaios Cienc., Cienc. Biol. Agrar. Saúde. 2014;18(1):55-63.

14. Vermund $\mathrm{SH}$, Wilson CM. Barriers to HIV testing - where next? Lancet. 2002; 360(9341):1186-7.

15. Freitas JP, Sousa LRM, Cruz MCMA, Caldeira NMVP, Gir E. Terapia com antirretrovirais: grau de adesão e a percepção dos indivíduos com HIV/Aids. Acta Paul Enferm. 2018;31(3):327-33.

16. Ferrer E, Curto J, Esteve A, Miro JM, Tural C, Murillas J, et al. Clinical progression of severely immunosuppressed HIV-infected patients depends on virological and immunological improvement irrespective of baseline status. J Antimicrob Chemother. 2015;70(12):3332-8.

17. Fox MP, Sanne IM, Conradie F, Zeinecker J, Orrell C, Ive $P$, et al. Initiating patients on ART at CD4 counts above 200 is associated with improved treatment outcomes in South Africa. NIH. 2011;24(13):2041-50.

18. Geocze L, Mucci S, Marco MA, Martins LAN, Citero VA. Qualidade de vida e adesão ao tratamento antiretroviral de pacientes portadores de HIV. Rev Saude Publica. 2010;44(4):743-9.
19. Silva JVF, Nascimento Júnior FJM, Rodrigues APRRA. Fatores de não adesão ao tratamento antirretroviral: desafio de saúde pública. Ciências Biológicas e da Saúde. 2014;2:165-75.

20. Ministério da Saúde. Boletim Epidemiológico de HIV/ AIDS. Brasília; 2018. 